\title{
En torno a la Medicina Ocupacional
}

\author{
On the scope of occupational health.
}

Para buen número de niños/niñas y adolescentes, de varias generaciones, el primer contacto con la Medicina Ocupacional surgía de la lectura del libro "De la Tierra a la Luna" (1), en los párrafos finales del capítulo XIV, cuando Julio Verne matiza su relato con "anotaciones de experto" sobre temas centrales a daños y riesgos

ocasionados por el trabajo. Destaca el escritor, que la prodigiosa construcción del tubo de lanzamiento del vagón espacial, amenazada por enfermedades tropicales y por imprudencias individuales en trabajos peligrosos que ocasionan inevitables pérdidas de vidas, había acumulado un bajísimo promedio de accidentes fatales por " 200000 Francos de salarios", increíblemente similar a los de las mejores Naciones de Europa, incluyendo Francia. Verne entrega argumentos que conducen al lector -cual lazarillos-, incitándolo, particularmente cuando tiene vocación por la medicina, a pensar que es posible y conveniente construir estándares para homogenizar lo heterogéneo, que el trabajo tiene una interfase de riesgo con la salud, la enfermedad y la muerte; y que nada es tan inexorable que no pueda ser modificado a través de la ciencia, la medicina y la acción política.

En él número anterior y en el presente número se publican valiosos artículos sobre Medicina Ocupacional. En este caso, apoyar este editorial de la Revista Médica Herediana citando a Julio Verne (1), fallecido en 1905, y probablemente el más leído de los novelistas franceses, resulta ampliamente justificado, porque la Medicina Ocupacional es uno de los capítulos de la Medicina más abiertos al interés general de la cultura.

En los estudios universitarios, los referentes históricos de la Medicina Ocupacional son Ramazzini, Hipócrates y Galeno (2). En el Perú, y especialmente en la Universidad Peruana Cayetano Heredia, el referente principal es su primer Decano de la Facultad de Medicina Dr. Alberto Hurtado Abadía, a quien el Perú debe la creación del Instituto de Salud Ocupacional en 1940.

En este número, en el artículo de Contribución Especial, Gomero R y colLa medicina ocupacional en los últimos tiempos, revisan el nuevo horizonte de esta especialidad como conocimiento, políticas públicas en marcha, y creciente posibilidades profesionales y académicas.

La confiabilidad de la estructura de Datos-Información-Conocimiento, imprescindible para investigar, analizar y evaluar situaciones, es puesta bajo escrutinio en el trabajo de Pestana $\mathrm{C}$ y col Concordancia entre el diagnóstico médico y la codificación de informática, considerando el CIE-10, en el Hospital Nacional Cayetano Heredia, Lima-Perú (3); este trabajo pone en agenda la necesidad de contar con estrategias y estructuras abocadas a cautelar la calidad de la información en los sistemas hospitalarios. En esta misma línea, Gomero R y col en La historia médico-ocupacional como herramienta de diagnóstico (4), presentan las ventajas de trabajar esta parte de la historia clínica como un esfuerzo sistematizado.

La Medicina Ocupacional se interesa generalmente por los problemas de profesiones y ocupaciones diferentes a la medicina, tal como ocurre con el trabajo de Palomino JC y col El trabajo a turnos como factor de riesgo para lumbago en un grupo de trabajadores peruanos, publicado en otro número de este volumen (5). 


\section{González del Carpio Diego}

Como signo del momento que vive la Medicina Ocupacional, como campo de conocimiento, subrayamos que tres artículos miran la salud ocupacional hacia dentro de la misma medicina. Gomero R y col desarrollan un tema reciente: El Síndrome de Burnout en personal sanitario de los hospitales de la empresa minera de Southern Perú Copper Corporation (6). El trabajo pone en valor, el potencial riesgo para la salud mental que conlleva, en ocasiones, el ambiente de trabajo.

En este número, Flores $\mathrm{C}$ y col en su artículo Conocimientos sobre bioseguridad en estudiantes de medicina de una universidad peruana identifican un nivel creciente de conocimientos que van alcanzando los estudiantes de medicina a medida que se acercan al internado (7).

Finalmente, como Tema de Revisión, Mendoza y col en Transmisión de los virus de la inmunodeficiencia adquirida, hepatitis $B$ y hepatitis-C-por exposiciones laborales en trabajadores de salud: Aspectos de profilaxis pre y post exposición,desarrollan extensamente el estado del arte en este tema de vibrante actualidad (8).

La variedad de artículos sobre Medicina Ocupacional admitidos a publicación en la Revista Médica Herediana, corrobora que existen numerosas oportunidades de trabajo y valor aplicativo de los hallazgos en el campo de Medicina Ocupacional. Creo, sin embargo, que a la disposición de llevar hacia dentro de las profesiones médicas la investigación sobre medicina ocupacional, como las que se presentan en este volumen de Revista Médica Herediana, tienen que sumarse acciones profesionales simples y efectivas, aplicables al trabajo corriente.

Hace pocas semanas, al iniciar mi presentación en una Conferencia Internacional en un importante país extranjero, invité al respetable auditorio, que ya llevaba 100 minutos sentado, a ponerse en pie, empinarse unas cuantas veces sobre sus metatarsos para dar descanso a sus músculos y mejorar el retorno venoso y el ánimo de estar presentes, tomó apenas un par de minutos, pero pudieron quebrar el cansancio y prestarme atención, terminada la conferencia, algunos se sintieron muy aliviados y agradecieron. Entonces pensé, los médicos hemos creado una infinidad de medidas de higiene industrial que jamás usamos con nosotros mismos, hasta los oficios religiosos tienen más movimiento corporal que una conferencia. Sería bueno empezar a remplazar las rutinas tradicionales, por otras que aseguren eficiencia y comodidad.

\section{REFERENCIAS BIBLIOGRÁFICAS}

1. Verne J. De la Terre a la Lune. http:// www.gutenberg.org/dirs/etext97/7lune09.txt (Fecha de acceso: 18 de diciembre del 2005).

2. Gomero R, Llap C. La medicina ocupacional en los últimos tiempos. Rev Med Hered 2005; 16 (4):273-275.

3. Pestana C, Llanos L, Cabello E, Lecca L Concordancia entre el diagnóstico médico y la codificación de informática, considerando el CIE-10, en el Hospital Nacional Cayetano Heredia, Lima-Perú. Rev Med Hered 2005; 16 (4): 239-245.

4. Gomero R, Llap C, La historia médico-ocupacional como herramienta de diagnóstico. Rev Med Hered 2005;16 (3):199-201.

5. Palomino JC, Ruiz F, Navarro G, Dongo F, Llap C,
Gomero R. El trabajo a turnos como factor de riesgo para Lumbago un grupo de trabajadores peruanos. Rev Med Hered 2005; 16 (3):184-189.

6. Gomero R, Palomino J, Ruiz F. El Síndrome de Burnout en personal sanitario de los hospitales de la empresa minera de Southern Perú Copper Corporation. Rev Med Hered 2005; 16 (4) :233-238.

7. Flores C, Samalvides F. Conocimientos sobre bioseguridad en estudiantes de medicina de una universidad peruana. Rev Med Hered 2005;16 (4):253259.

8. Mendoza A, Samalvides F. Transmisión de los virus de la inmunodeficiencia adquirida, hepatitis B y hepatitisC-por exposiciones laborales en trabajadores de salud: Aspectos de profilaxis pre y post exposición. Rev Med Hered 2005; 16 (4):276-285.

Diego González del Carpio ${ }^{1}$

1 MD, MPH, Doctor en Medicina. Profesor Principal de la Universidad Peruana Cayetano Heredia. 